\title{
Minority Report e o governo da distopia algorítmica
}

DOI: https://doi.org/10.22409/pragmatizes.v10i19.42292

\section{Marcelo Cizaurre Guirau ${ }^{1}$}

\section{Ana Elisa Sobral Caetano da Silva Ferreira ${ }^{2}$}

Resumo: Tendo como objetivo refletir sobre o ideário de vigilância e de livre-arbítrio frente às tecnologias digitais nas últimas duas décadas, analisaremos as encruzilhadas de ambivalências sintetizadas no dispositivo Pré-Crime criado em Minority Report, conto de Philip K. Dick publicado em 1956 e adaptado para o cinema por Steven Spielberg em 2002, como uma figuração literária de impasses também capturados conceitualmente em noções como "capitalismo de vigilância" (ZUBOFF, 2019) e "governamentalidade algorítmica" (ROUVROY; BERNS, 2018). Em meio ao labirinto conceitual derivado de um cenário novo e dinâmico, podemos voltar o olhar para a ficção científica à procura de exercícios de imaginação especulativa consistentes que tentem mapear, por meio da construção de universos ficcionais futurísticos alternativos à nossa realidade, alguns dos dilemas que constituem a nossa experiência presente. Assim, leremos o conto Minority Report como uma tradução formal de impasses e uma construção ficcional na qual utopia e distopia podem ser lados da mesma moeda (LARREGUE; WANNYN; DARTIGUES, 2019).

Palavras-chave: Capitalismo de Vigilância; Governamentalidade algorítmica; Distopia; Ficção Científica; Philip K. Dick.

\section{Minority Report y el gobierno de la distopía algorítmica}

Resumen: Con el objetivo de reflexionar sobre las ideas de vigilancia y libre albedrío frente a las tecnologías digitales en las últimas dos décadas, analizaremos la encrucijada de ambivalencias sintetizadas en el dispositivo Precrimen creado en Minority Report, un cuento de Philip K. Dick publicado en 1956 y adaptado para el cine por Steven Spielberg en 2002, como figuración literaria de puntos muertos también capturados conceptualmente en nociones como "capitalismo de vigilancia" (ZUBOFF, 2019) y "gubernamentalidad algorítmica" (ROUVROY; BERNS, 2018). En medio del laberinto conceptual derivado de un escenario nuevo y dinámico, podemos recurrir a la ciencia ficción en busca de ejercicios consistentes de imaginación especulativa que intenten mapear, a través de la construcción de universos futuristas de ficción alternativos a nuestra realidad, algunos de los dilemas que constituyen nuestra experiencia actual. Por lo tanto, leeremos el cuento Minority Report como

\footnotetext{
${ }^{1}$ Marcelo Cizaurre Guirau. Doutor em Letras pela Universidade de São Paulo (USP). Professor do Instituto Federal de Educação, Ciência e Tecnologia São Paulo (IFSP), Brasil. E-mail: cizaurre@ifsp.edu.br - https://orcid.org/0000-0002-3148-7910

${ }^{2}$ Ana Elisa Sobral Caetano da Silva Ferreira. Doutoranda em Linguística (UFSCAR); professora do Instituto Federal de Educação, Ciência e Tecnologia São Paulo (IFSP), Brasil. E-mail: anaelisaferreira@ifsp.edu.br - https://orcid.org/0000-0003-4633-632X
} 
una traducción formal de puntos muertos y una construcción ficticia en la que la utopía y la distopía pueden ser lados de la misma moneda (LARREGUE; WANNYN; DARTIGUES, 2019).

Palabras claves: Capitalismo de vigilancia; Gubernamentalidad algorítmica; Distopía; Ciencia ficción; Philip K. Dick.

\title{
Minority Report and the rule of the algorithmic dystopia
}

\begin{abstract}
With the purpose of reflecting about ideason surveillance and free-will in the face of the digital technology of the last two decades, we intend to analyze the crossway of ambivalences condensed in the Pre-Crime system created in Minority Report, a short-story by Philip K Dick published in 1956 and screen played by Seven Spielberg in 2002, as a literary figuration of impasses also conceptually captured in notions such as "surveillance capitalism" (ZUBOFF, 2019) and "algorithmic governmentality" (ROUVROY; BERNS, 2013). Encircled by the conceptual labyrinth derived from a new and dynamic landscape, we turn our gaze to science fiction in search of consistent exercises in speculative imagination which try to map, through the construction of futuristic fictional universes alternative to our reality, some of the dilemmas which constitute our present experience. In this way, we intend to read the short-story Minority Report as a formal translation of impasses and as a fictional construction in which utopia and dystopia can be sides of the same coin (LARREGUE; WANNYN;DARTIGUES, 2019).
\end{abstract}

Keywords: Surveillance capitalism; Algorithmic governmentality; Dystopia; Science Fiction; Philip K. Dick.

\section{Minority Report e o governo da distopia algorítmica}

\section{Introdução}

No início dos anos 90, Pierre Lévy lançou um livro dedicado às tecnologias da inteligência cuja reflexão sobre o futuro do pensamento na era da informática também propõe, no capítulo das coletividades pensantes, o fim da metafísica. Nas palavras do autor, "A ecologia cognitiva substitui as oposições radicais da metafísica por um mundo matizado, misturado, no qual efeitos de subjetividade emergem de processos locais e transitórios" (LÉVY, 2016, p. 170, grifos do autor).

Isto é, Lévy, ao utilizar a metáfora do cérebro como computador (memória de trabalho), baseia-se nas teorias da psicologia cognitiva sobre memória para construir sua tese de uma ecologia cognitiva do pensamento fundido a dispositivos técnicos. Para o autor, "pensar é um devir coletivo no qual misturam-se homens e coisas" (LÉVY, 2016, p. 171). Tal mistura, na era da informática, daria vazão a uma inteligência coletiva mediada pela 
informática e regida por uma tecnodemocracia.

A visão utópica e entusiasta de Lévy se choca com a posição quase distópica de Régis Debray (2000, p. 30), que afirma ser a "ciberdemocracia" "o sonho do tecnocrata que esqueceu sua parte animal". Em meio ao labirinto conceitual derivado de um cenário novo e dinâmico como o que esses pensadores buscam investigar, podemos voltar o olhar para a ficção científica à procura de exercícios de imaginação especulativa consistentes que tentem mapear, por meio da construção de universos ficcionais futurísticos alternativos à nossa realidade, alguns dos impasses que vêm marcando 0 debate filosófico acima referido. Dessa forma, analisaremos o conto Minority Report, escrito por Philip K Dick, como uma formalização de impasses e uma construção na qual utopia e distopia podem ser lados da mesma moeda (LARREGUE;

WANNYN; DARTIGUES, 2019).

Publicado em 1956 e adaptado para o cinema por Steven Spielberg em 2002 - com roteiro de Scott Frank e Jon Cohen -, Minority Report traz um mundo em que o crime foi praticamente extinto pela Divisão PréCrime, que, por meio de um dispositivo formado pelas visões do futuro próximo feitas por três precogs e filtradas por um sistema computadorizado, faz prisões momentos antes do crime ser concretizado. Assim, milhares de pessoas são condenadas por crimes que efetivamente não cometeram, situação que arma um dilema relacionado a questões sobre livrearbítrio: por um lado, a ação da PréCrime salva vidas; por outro, pessoas são detidas e condenadas por ações apenas previstas, o que retira delas a chance de tomar um caminho diferente e evitar a ação violenta: elas estão, dessa forma, presas a um destino imutável e são condenadas com base em uma pré-visão de um futuro tido como monolítico.

Todo o sistema é posto em xeque quando Anderton, o chefe e um dos criadores da Divisão Pré-Crime, intercepta uma previsão de que ele cometeria um assassinato. Um intrincado jogo de interesses, conduzido por diversos personagens, se desdobra a partir daí. Anderton é lançado, pelo próprio sistema que ele 
luta para manter, em um conflito entre livre-arbítrio e a crença na infalibilidade do mecanismo anticrimes que vem garantindo a segurança do mundo em que vive.

Ao considerarmos a narrativa como distópica, concordamos com a afirmação de Botello (2018) para pensar a contemporaneidade:

As distopias permitem dramatizar as tensões, esperanças e medos que vivem as sociedades contemporâneas. Além disso, elas proporcionam espaços cognitivos que permitem visualizar as morfologias da dominação e do poder. Propiciam cenários de resistências ao futuro, mas também projetos que buscam transformar ficção em realidade. (p. 232)

A proposta de uma instituição que prevê e evita crimes antes que eles sejam cometidos flerta com 0 sonho utópico de um entusiasta tecnológico que acredita no poder irrefutável da ciência. A trajetória do personagem Anderton, no entanto, coloca dúvidas ao leitor quando joga com a possibilidade da falha.

Logo nas primeiras linhas do conto, instala-se uma dialética entre livre-arbítrio e Estado em que a autonomia individual é abolida em nome do interesse público e da garantia de funcionamento perfeito do
Sistema Pré-Crime. Dessa forma, o conto constrói uma aporia: pressupondo que o sistema funcione, a intervenção policial antes do fato, dado como certo, permite a salvação da vítima e a prisão do criminoso; por outro lado, o preso pagará por um crime que não cometeu e que poderia não ter sido cometido. Isto é, o sistema, ao intervir na iminência do crime, retira do indivíduo a autonomia do julgamento sobre sua ação. Como Anderton explica a Witwer, "a execução do crime em si é absolutamente metafísica. Afirmamos que são condenáveis" (DICK, 2012, p. 129). Assim, no universo do conto, está abolido um dos alicerces fundamentais do direito penal em sociedades democráticas: a presunção de inocência. Uma das máximas do direito, de que todo indivíduo é inocente até que se prove o contrário, pressupõe a materialidade do crime para a condenação. Essas salvaguardas jurídicas são abolidas em Minority Report, mas em nome de uma utopia: a extinção dos crimes. $\mathrm{O}$ conto cria, dessa maneira, um dilema em que a eliminação de um direito fundamental traz um benefício coletivo inegável e dos mais desejados. 
Anderton se gaba da redução de 99.8 por cento dos crimes graves (DICK, 2012, p. 131) e o leitor é levado, nesse ponto da narrativa, a compartilhar do entusiasmo de Witwer pelo Sistema Pré-Crime: "Um assassinato em cinco anos - Witwer retomava a confiança. Um recorde bastante impressionante... motivo de orgulho" (DICK, 2012, p. 131). Aqui vemos a atuação de um pêndulo de incertezas na economia do conto: Witwer, após ter suas convicções questionadas pelas primeiras dúvidas colocadas por Anderton e pela visão da triste figura dos precogs, retoma sua confiança como nos informa o narrador - com os números impressionantes da PréCrime.

O sistema todo se sustenta, ética e juridicamente, na premissa de infalibilidade do dispositivo Pré-Crime. Estabelece-se, assim, uma metafisica da ciência, representada no conto pelo aparato de precognição, em que a certeza científica é inquestionável.

No começo do conto, Anderton, já certo das intenções de Witwer de substituí-lo, evoca, com ironia, o pouco

\footnotetext{
${ }^{3}$ No original: "'One murder in five years.' Witwer's confidence was returning. 'Quite an impressive record...something to be proud of'."
}

conhecimento do seu adversário sobre o funcionamento do sistema: "Já está familiarizado com a teoria do PréCrime, é claro. Suponho que seja ponto pacífico"” (DICK, 2012, p. 129). Além de contribuir para a construção, no texto, do antagonismo de Anderton em relação a Witwer, essa pergunta indireta cria o contexto para que se apresente ao leitor a teoria que sustenta o Sistema Pré-Crime:

Tenho as informações disponíveis ao público - respondeu Witwer. Com o auxílio de seus mutantes precognitivos, você aboliu com ousadia e êxito o sistema punitivo pós-crime, baseado em presídios e penalidades. Como todos sabemos, a punição nunca foi muito dissuasiva, e servia de pouco consolo a uma vítima já morta . (DICK, 2012, p. 129)

A fala de Witwer, que denota uma adesão entusiasmada à imagem pública de êxito construída da teoria do Pré-Crime, estabelece esse personagem como um dos extremos do pêndulo de incertezas que move a

\footnotetext{
${ }^{4}$ No original: "You're acquainted with the theory of precrime, of course. I presume we can take that for granted."

${ }^{5}$ No original: "I have the information publicly available", Witwer replied. "With the aid of your precog mutants, you've boldly and successfully abolished the post-crime punitive system of jails and fines. As we all realise, punishment was never much of a deterrent, and could scarcely have afforded the comfort to a victim already dead."
} 
narrativa. Nas linhas seguintes, surgem, do diálogo entre Witwer e Anderton, os primeiros obstáculos à tese da infalibilidade que constitui 0 amparo legal e ético do Sistema PréCrime :

- Você já deve ter notado o inconveniente legal básico da metodologia do Pré-Crime. Estamos prendendo indivíduos que não infringiram lei alguma.

- Mas com certeza vão infringir Witwer afirmou com convicção.

- Felizmente não infringem... porque os capturamos primeiro, antes que possam cometer um ato de violência. Portanto, a execução do crime em si é absolutamente metafísica. Afirmamos que são condenáveis. Eles, por outro lado, afirmam eternamente que são inocentes. $\mathrm{E}$, em certo sentido, são inocentes.

(...)

- Em nossa sociedade, não temos qualquer crime grave - prosseguiu Anderton -, mas temos, sim, um campo de detenção cheio de supostos criminosos ${ }^{6}$. (DICK, 2012, p. 129)

\footnotetext{
${ }^{6}$ No original: "You've probably already grasped the basic legalistic drawback to precrime methodology. We're taking in individuals who have broken no law." "But surely, they will," Witwer affirmed with conviction. "Happily, they don't - because we get to them first, before they can commit an act of violence. So the commission of the crime itself is absolute metaphysics. We can claim they are culpable. They, on the other hand, can eternally claim they're innocent. And, in a sense, they are innocent." (...) "In our society, we have no major crimes," Anderton went on, "but we do have a detention camp full of would-be criminals."
}

\section{A distopia algorítmica no governo da vida}

Guardando semelhanças com a

Divisão Pré-Crime apresentada no conto de Dick, nossa realidade conta com um sistema ainda mais complexo e abrangente. A world wide web carrega em seu próprio nome o ideário de potência e a ambição de uma rede que pretende alcançar todo o globo por meio de uma linguagem intrincada e opaca: a programação algorítmica.

Inicialmente idealizada como um espaço de troca e coletividade (LÉVY, 2016 ; 2014), a internet, colonizada pela lógica capitalista, tornou-se um espaço onde empresas como Google, Amazon, Facebook e Apple (GAFA) impõem suas práticas no ciberespaço, escrevendo seus próprios termos e promovendo uma mutação no sistema capitalista que a pesquisadora Shoshana Zuboff (2015, 2019) nomeia como "capitalismo de vigilância". Tal sistema baseia-se na coleta e cruzamento dos dados e metadados de seus usuários para traçar um perfil a fim de personalizar seus serviços. Entretanto, esse processo de personalização é, na realidade, uma ferramenta para produção de previsões sobre futuras 
GUIRAU, Marcelo Cizaurre; FERREIRA, Ana Elisa S. C. da S. Minority Report e o governo da distopia algorítmica.PragMATIZES - Revista Latino-Americana de Estudos em Cultura, Niterói/RJ, Ano 10, n. 19, p. 232-248, set. 2020.

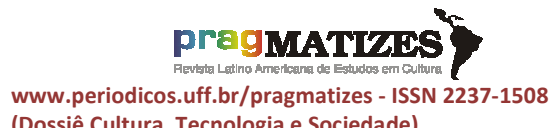

(Dossiê Cultura, Tecnologia e Sociedade) necessidades, escolhas e tendências de cada usuário ou de um grupo específico.

O capitalismo de vigilância tem início
com a descoberta do excedente
comportamental. Mais dados de
comportamento são colhidos do que
os necessários para a melhoria de
serviços. O excedente alimenta a
inteligência das máquinas - novo
meio de produção - que fabrica
previsões do comportamento do
usuário. Isso significa que esses
produtos serão vendidos no mercado
de comportamentos futuros.
(ZUBOFF, 2019, p. 96) (tradução
nossa)

Atualmente, as transações humanas dependem cada vez mais da mediação de tecnologias digitais. De sistemas de bancos ao acesso de plataformas escolares, passando pelas mídias sociais, a programação algorítmica modificou o modo como interagimos com o espaço online e offline. Zuboff afirma que tal mediação "representa simbolicamente eventos, objetos e processos, que se tornam passíveis de serem conhecidos e compartilhados de uma nova maneira" (ZUBOFF, 2018).

Essa nova maneira de compartilhamento de dados produz o que Zuboff (2019) chama de "behavioral surplus"7, ou excedente

\footnotetext{
${ }^{7}$ A autora estabelece um diálogo com o conceito de mais-valia (surplus-value) filiando-
}

comportamental, a matéria prima de um capitalismo baseado na vigilância. Essa mutação do sistema capitalista tem desdobramentos profundos na modulação de comportamentos dos indivíduos (SILVEIRA, 2017) e apresenta-se como um novo modo de afetação pré-consciente da ação humana (ROUVROY; BERNS, 2018).

Zuboff (2019) afirma que sob o capitalismo de vigilância, os meios de produção correspondem aos meios de modificação comportamental. Ela denomina o poder dessas empresas como "instrumentarismo 8 ", definindo-o como a instrumentação e instrumentalização do comportamento humano com o propósito de modificar, prever, monetizar e controlar.

A autora afirma ainda que capitalismo de vigilância não é apenas uma faceta diferente do capitalismo e sim um golpe contra a democracia, não no sentido político de um golpe de Estado (coup d'état), mas de um golpe

se a corrente materialista dialética ao utilizar termos como surplus e means of production, propondo uma atualização desses conceitos frente as mudanças tecnológicas. Entretanto, entendemos que o conceito surplus behavioral está relacionado ao produto excedente da navegação, os rastros deixados pelo internauta.

\footnotetext{
${ }^{8}$ No original, "instrumentarianism" (ZUBOFF, 2019).
} 
involuntário e inconsequente (coup de gens) perpetrado por indivíduos fascinados por tecnologia em movimento de derrubada dos direitos humanos em troca de conforto e agilidade tecnológica.

A dinâmica do poder instrumentário descrito por Zuboff (2019) dialoga com o movimento civilizatório proposto por Debray (2019). Instaura-se, assim, um jogo de espionagem sem testemunhas que cria necessidades, desumaniza as experiências e direciona comportamentos de um modo silencioso e persistente para que as bases da civilização sejam definidas segundo as práticas do capitalismo de vigilância.

A vitória pode ser declarada quando, em vez de uma, existe apenas a civilização, sua língua uma língua franca e sua moeda uma medida comum. Quando ela pode se retirar para sua terra natal e ainda ser um farol. Quando tribos alógenas adotam seus tiques, hábitos e normas, sem nem mesmo perceberem que estão copiando. Quando o comandante não precisa mais comandar. Uma civilização venceu quando todas as suas formas se tornam naturais. (DEBRAY, 2019, p. 14) (tradução nossa)

A crença na infalibilidade da programação algorítmica faz parte do processo civilizatório do homem contemporâneo, a diferença é que esse processo acontece em um espaço que antes não existia: 0 ciberespaço.

A linha tênue entre o real e o virtual foi apagada por práticas naturalizadas em objetos técnicos cada vez mais portáteis, como celulares que coletam a todo instante dados de seus usuários. A naturalização do uso desses objetos,tidos como inofensivos,faz parte da engrenagem de um sistema governado por algoritmos. "A inofensividade, a 'passividade' do governo algorítmico é apenas aparente: o governo algorítmico 'cria' uma realidade ao menos tanto quanto registra" (ROUVROY; BERNS, 2018, p. 127). Realidade que é fruto de um minucioso cruzamento de dados feito por algoritmos cada vez mais autônomos, vide o desenvolvimento da inteligência artificial e do machine learning (O'NEIL, 2016).

O'Neil (2016) explica como a programação algorítmica é definitiva em decisões que vão do aceite na universidade, passando pela aprovação de créditos bancários, até à escolha dos candidatos à presidência. Em uma sociedade onde o data mining 
é responsável pela construção de perfis que direcionam as escolhas dos sujeitos, tanto online quanto offline, impõe-se a pergunta sobre o quanto os indivíduos estariam dispostos a sacrificar do ideário do livre-arbítrio em favor de uma lógica de personalização. Segundo Rouvroy e Berns (2018, p. 120),

\begin{abstract}
O governo algorítmico parece, por essa razão, assinar a conclusão de um processo de dissipação das condições espaciais, temporais, e linguísticas da subjetivação e da individuação em benefício de uma regulação objetiva, operacional, das condutas possíveis.
\end{abstract}

Isto é, diante da lógica da sociedade governada pela linguagem algorítmica, quase tudo é reduzido a cálculos para prever e até modificar comportamentos em um processo de dessubjetivação do indivíduo, atravessado pelo ideário da matemática como linguagem universal (FINN, 2017). A utilização de algoritmos como receitas ou sequências instrucionais para calcular um determinado resultado não é novidade na matemática; porém, as ciências computacionais, juntamente com a popularização da internet, fomentaram o debate sobre como a programação algorítmica apresenta consequências dentro e fora do ciberespaço. Para Doneda e Almeida (2018, p. 141),

algoritmos são basicamente um conjunto de instruções para realizar uma tarefa, produzindo um resultado final a partir de algum ponto de partida. Atualmente, os algoritmos embarcados em sistemas e dispositivos eletrônicos são incumbidos cada vez mais de decisões, avaliações e análises que têm impactos concretos em nossa vida. [...] Quanto mais aumentam a sofisticação e a utilidade dos algoritmos, mais se mostram "autônomos", chegando a dar a impressão de que existe uma "máquina pensante" por detrás de alguns raciocínios misteriosos, uma imagem que remonta aos primórdios da informática.

A imagem da máquina pensante e seus raciocínios misteriosos também faz parte da narrativa do conto Minority Report, que se apoia no ideário da ciência como receita para a solução de crimes. No entanto, o dispositivo de precognição em que todo o Sistema Pré-Crime se baseia constitui-se de uma estranha combinação e elementos sobrenaturais e físicos. As previsões partem de seres cognoscentes que inexplicavelmente possuem a capacidade de ver o futuro. O tributo pago por esse dom é a completa inatividade física e mental. Os precogs são apresentados assim pelo narrador: 
$\mathrm{Na}$ penumbra, os três dementes estavam sentados, balbuciando. Cada declaração incoerente, cada sílaba aleatória, era analisada, comparada, reorganizada em forma de símbolos visuais, transcrita em cartões perfurados convencionais e ejetada para dentro de diversas fendas codificadas. Durante todo o dia os dementes balbuciavam, aprisionados em suas cadeiras especiais de encosto alto, mantidos numa única posição rígida por tiras de metal, feixes de fios e grampos. Suas necessidades físicas eram atendidas automaticamente. Não tinham nenhuma necessidade espiritual. Vegetativos, murmuravam, cochilavam e existiam. Suas mentes eram embotadas, confusas, perdidas nas sombras.

Mas não nas sombras de hoje. As três criaturas gaguejantes, tartamudeantes, com cabeças inchadas e corpos debilitados, contemplavam 0 futuro. $\mathrm{O}$ maquinário analítico registrava suas profecias e, à medida que os três dementes precogs falavam, as máquinas ouviam com atenção ${ }^{9}$. (DICK, 2012, p. 129, 130)

\footnotetext{
${ }^{9}$ No original: "In the gloomy half-darkness the three idiots sat babbling. Every incoherent utterance, every random syllable, was analysed, compared, reassembled in the form of visual symbols, transcribed on conventional punch cards, and ejected into various coded slots. All day long the idiots babbled, imprisoned in their special high-backed chairs, held in one rigid position by metal bands, and bundles of wiring, clamps. Their physical needs were taken care of automatically. They had no spiritual needs. Vegetable-like, they muttered and dozed and existed. Their minds were dull, confused, lost in shadows.
}

But not shadows of today. The three gibbering, fumbling creatures with their enlarged head and wasted bodies, were contemplating the future. The analytical machinery was recording prophecies, and as the three precog idiots talked, the machinery carefully listened".
Em termos composicionais, a demência dos precogs se explica por dois motivos: por um lado, ela transfere para a parte do "maquinário analítico" do dispositivo a responsabilidade pela interpretação dos dados, uma vez que as visões aparecem para os precogs de maneira desordenada e eles não dispõem de capacidade cognitiva para lê-las. Caso a possuíssem, os computadores que atuam na decifração das imagens do futuro não teriam razão de existir no conto. Assim, não haveria um dispositivo analítico, mas apenas a presença do sobrenatural, encarnada na figura dos precogs ${ }^{10}$; por outro lado, a demência desses seres especiais reforça sua aura oculta e sobrenatural - eles são admirados e quase santificados pelos seus dons, fato que é muito mais explorado na versão cinematográfica do conto.

\footnotetext{
${ }^{10}$ A hipótese do controle das interpretações do futuro originada da demência dos precogs é confirmada por Anderton: "O talento absorve tudo. O lobo da percepção extrassensorial reduz o equilíbrio da área frontal. Mas o que isso nos importa? Temos suas profecias. Eles transmitem o que precisamos. Não entendem nada, mas nós entendemos" (DICK, 2012, p. 130). No original: "The talent absorbs everything; the esp-lobe shrivels the balance of the frontal area. But what do we care? We get their prophecies. They pass on what we need. They don't understand any of it, but we do".
} 
GUIRAU, Marcelo Cizaurre; FERREIRA, Ana Elisa S. C. da S. Minority Report e o governo da distopia algorítmica.PragMATIZES - Revista Latino-Americana de Estudos em Cultura, Niterói/RJ, Ano 10, n. 19, p. 232-248, set. 2020.

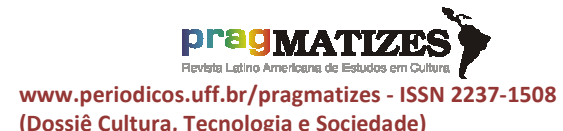

(Dossiê Cultura, Tecnologia e Sociedade)
Essa conjunção exótica de elementos sobrenaturais e pretensamente científicos que define, no conto, o dispositivo de precognição de crimes é retomada em outro trecho da narrativa. Em cena de grande apelo visual, Anderton, enquanto examina, de seu esconderijo em um hotel, um dente quebrado em um espelho também quebrado, escuta em uma transmissão radiofônica as palavras oficiais sobre o Sistema Pré-Crime, que são repetidas em diferentes aparelhos em vários quartos vizinhos:

o sistema de três precogs tem origem nos computadores de meados deste século. Como são verificados os resultados de um computador eletrônico? Pela entrada de dados num segundo computador com estrutura idêntica. Mas dois computadores não são suficientes. Se cada computador chegar a respostas diferentes, é impossível saber a priori qual é a correta. A solução, baseada num criterioso estudo estatístico, é usar um terceiro computador para verificar os resultados dos dois primeiros. Desse modo, obtém-se o chamado relatório majoritário. É possível supor, com alta probabilidade, que a concordância entre dois dos três computadores indica qual dos resultados alternativos é exato. Não seria provável que dois computadores chegassem a soluções incorretas idênticas...

[...]

a unanimidade entre os três precogs é um fenômeno desejado, mas raramente alcançado, explica 0 comissário interino, Witwer. É muito mais comum obtermos um relatório majoritário colaborativo, de dois precogs, acrescentado de um relatório minoritário com uma leve variação, geralmente relativa a tempo e local, do terceiro mutante. Isso é explicado pela teoria dos futuros múltiplos. Caso existisse apenas uma via temporal, a informação precognitiva não teria a menor importância, uma vez que, ao possuirmos tal informação, não haveria possibilidade alguma de alterar o futuro. No trabalho da Divisão Pré-Crime, temos de supor, em primeiro lugar... ${ }^{11}$ (DICK, 2012, p. 149)

Essas palavras, despejadas de rádios que cercam Anderton em quartos vizinhos ao seu, procuram

${ }^{11}$ No original: “....the system of three precogs finds its genesis in the computers of the middle decades of this century. How are the results of an electronic computer checked? By feeding data to a second computer of identical design. But two computers are not sufficient. If each computer arrived at a different answer, it is impossible to tell a priori which is correct. The solution, based on a careful study of statistical method, is to utilize a third computer to check the results of the first two. In this manner, a socalled majority report is obtained. It can be assumed with fair probability that the agreement of two out of three computers indicates which of the alternative results is accurate. It would not be likely that two computers would arrive at identically incorrect solutions -

(...)

'....unanimity of all three precogs is a hoped-for but seldom achieved phenomenon, actingCommissioner Witwer explains. It is much more common to obtain a collaborative majority report of two precogs, plus a Minority Report of some slight variation, usually with reference to time or place, from the third mutant. This is explained by the theory of multiple-futures. If only one time-path existed, precognitive information would be of no importance, since no possibility would exist, in possessing this information, of altering the future. In the Precrime Agency's work we must first of all assume -'"'. 
GUIRAU, Marcelo Cizaurre; FERREIRA, Ana Elisa S. C. da S. Minority Report e o governo da distopia algorítmica.PragMATIZES - Revista

Latino-Americana de Estudos em Cultura, Niterói/RJ, Ano 10, n. 19, p. 232-248, set. 2020.

trazer o selo de garantia empírica concedido pelo caráter pretensamente científico de um sistema computadorizado "basead[o] num criterioso estudo estatístico". Na cena, um contraste se dá entre o conteúdo dessas palavras e a figura de Anderton, ambivalentemente avalizador e obstáculo à confiabilidade no sistema que as palavras de Witwer tentam reafirmar. Anderton, tendo acesso a previsão de seu próprio crime, procura fugir dessa previsão, o que, inicialmente, provaria um erro do sistema. O confronto com sua imagem no espelho quebrado enquanto ouve $o$ discurso em defesa do sistema PréCrime de seu esconderijo captura em rico quadro a encruzilhadas de ambivalências que o conto cria.

Essa ambivalência entre elementos racionais e irracionais que $o$ conto cria na figura no dispositivo de previsão de crimes foi detectada por Theodor Adorno em seu estudo da coluna de astrologia do Los Angeles Times (ADORNO, 2008). Em seu estudo, Adorno procura evidenciar a “...configuração do racional e do irracional na astrologia" (ADORNO, 2008) e que à conclusão de que

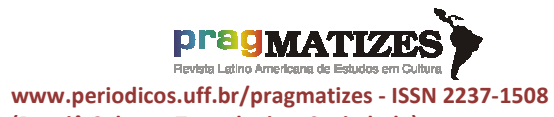

(Dossiê Cultura, Tecnologia e Sociedade)

de forma muito semelhante à indústria cultural, a astrologia tende a eliminar a distinção entre fato e ficção: seu conteúdo é muitas vezes exageradamente realista, ao mesmo tempo que sugere atitudes baseadas em fontes inteiramente irracionais, como o conselho de se evitar fechar negócios em determinado dia. (ADORNO, 2008, p. 59)

Alegoricamente, as ambivalências entre sobrenatural e empírico-científico sintetizadas no dispositivo Pré-Crimes figuram os impasses do processo de algoritimização da vida aqui apresentado em diversos exemplos. De fato, a dependência de elementos sobrenaturais (as visões dos precogs) confere ao sistema todo uma incontornável variável de incerteza que interdita o domínio completo da frieza analítica do algoritmo.

As ambivalências sobre a margem de certeza do sistema são mantidas até o final. Anderton, ao ver a relatório de um dos precogs que prevê sua ação homicida, cria um novo futuro em que ele decide não matar. Esse novo caminho interfere no próximo relatório, que o incorpora como dado. Ao final do conto, Anderton decide matar para não desacreditar o sistema. Dessa forma, cria-se um final ambivalente em que 
coexistem o livre-arbítrio, uma vez que Anderton se convence a matar para provar que o sistema funciona, e a confirmação do próprio sistema que restringe a autonomia humana, já que Anderton, de fato, comete 0 assassinato que está previsto de acontecer. Assim sendo, não se pode concluir que o conto se encerre com a vitória do livre-arbítrio, uma vez que, ainda que a decisão de matar seja consciente e planejada como uma medida necessária para evitar um mal maior, ela de fato cumpre a previsão dos precogs. A ambiguidade aqui é instrutiva, visto que sintetiza figurativamente os impasses de uma equação (livre-arbítrio $x$ racionalização total da experiência humana) para 0 qual ainda não se achou um resultado plenamente satisfatório.

\section{Conclusão: Minority Report e o} capitalismo de vigilância

Em um mundo governado por algoritmos, nos quais deposita-se a crença de infalibilidade da ciência, muitas vezes somos conduzidos, assim como Witwer, apenas por meio das informações que se tornam públicas, sem saber ao certo como o cruzamento de dados são responsáveis pela modulação de comportamentos e qual o seu alcance para definir decisões futuras.

Um exemplo real que se aproxima do mundo imaginado em Minority Report e retoma a discussão sobre justiça e livre-arbítrio é a utilização do software COMPAS, acrônimo de Correctional Offender Management Profiling for Alternative Sanctions $^{12}$, criado pela empresa estadunidense Equivant e que, segundo o manual do usuário disponível no site oficial da empresa ${ }^{13}$, funciona como um sistema de gerenciamento para profissionais da justiça criminal que tem por objetivo auxiliar decisões nos casos de préjulgamento, prisão e liberdade condicional. O COMPAS Core foi desenvolvido para analisar dados de homens e mulheres infratores que podem ou não estar em cárcere.

Ainda segundo o manual do usuário, os primeiros estudos para o desenvolvimento do software começaram em 1998 com base em

\footnotetext{
${ }^{12}$ Tradução: Gerenciamento de Perfis de Infratores para Penas Alternativas.

${ }^{13} \mathrm{http}: / /$ www.equivant.com/wpcontent/uploads/Practitioners-Guide-toCOMPAS-Core-040419.pdf. Acesso: 23 mar.2020.
} 


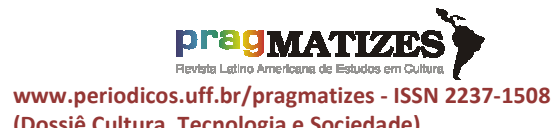

(Dossiê Cultura, Tecnologia e Sociedade) dois modelos de risco: risco geral de reincidência e risco geral de reincidência violenta. $O$ modelo da programação do software tem como referência estudos que apontam que avaliações estatísticas tendem a ser superiores (grifo nosso) ao julgamento humano.

O software funciona cruzando os dados de casos específicos informados pelos profissionais da justiça criminal com informações já disponíveis no banco de dados. Assim, o software é capaz de calcular uma pontuação para cada indivíduo de acordo com os modelos de risco e definir qual seria a sentença mais justa diante dos resultados.

A empresa defende o ideário da big data e do machine learning como soluções mais precisas e menos tendenciosas para definir as sentenças. Entretanto, um estudo recente (DRESSEL; FARID, 2018) aponta que esse ideário não corresponde à realidade e afirma que as sentenças dadas pelo software equivalem a previsões feitas por pessoas com pouco ou nenhum conhecimento jurídico.

Assim como no conto de Dick, estamos diante da naturalização de um discurso que coloca a segurança à frente da privacidade e do livre arbítrio. Governos totalitários já utilizam a tecnologia digital para vigiar e punir seus cidadãos. $\mathrm{Na}$ China, por exemplo, foi adotado um sistema de pontuação, Sesame Credit, que cruza dados e avalia o comportamento de cada cidadão de acordo com suas finanças e suas relações com 0 governo. Segundo Zuboff (2019), o sistema produz um perfil holístico que avalia além de pagamentos de contas e empréstimos. Critérios como qualidade e quantidade de amigos, históricos de compras e nível escolar também interferem na qualificação do cidadão dentro do Sesame Credit.

As consequências dessa avaliação são tão profundas que pessoas com uma baixa pontuação são marginalizadas pelos próprios amigos, que temem ter seus números afetados. Assim como acontece no COMPAS, a lógica da desigualdade é propagada no Sesame Credit, já que o sistema dificulta a mobilidade social.

Os critérios de julgamento criminal no conto de Dick são muito mais sujeitos a deslizes do que os adotados pelos algoritmos, pois dependem das visões dos precogs e 
de um complexo sistema de checagens e rechecagens baseado em computadores. Entretanto, existe um caráter de interpretação que também apresenta vestígios na programação algorítmica. Tal interpretação está presente naquilo que lerardo (2018) define como a consciência do programador frente a um "modus cogitandi instrumental econômico-liberal insistente de um capitalismo que sempre transforma, mas que nunca altera seu princípio constante: a otimização de ganâncias e do poder econômico como um valor de si mesmo" (IERARDO, 2018, p. 28) (tradução nossa).

A colonização da internet se dá em um recorte histórico propício à falta de debate, especialmente aqueles que são considerados políticos. Jameson (2000), ao descrever a lógica do pósmodernismo como uma dominante cultural, aponta que a predileção pela estética "degradada" não acontece somente no campo cultural, na predileção por "seriados de TV e da cultura Reader's Digest", ressaltando que o pós-modernismo é, ao mesmo tempo, "necessariamente uma posição política, implícita ou explícita, com respeito à natureza do capitalismo multinacional" (JAMESON, 2000, p. 29)

Para Harari (2015), o livrearbítrio é a principal base do liberalismo, pois, segundo o autor, é o ideário da singularidade do indivíduo que permite que esse sistema funcione, tanto política quanto economicamente. O homem da pósmodernidade de Jameson ou do liberalismo de Harari naturalizaram práticas que prezam pela segurança individual, pela personalização e pela facilidade, mesmo que isso signifique sacrificar a privacidade.

A sociedade imaginada por Dick aceita a Divisão Pré-Crime tanto quanto a nossa aceita as políticas de privacidade das grandes empresas que controlam o fluxo de dados na internet. No início da narrativa, somos informados de que o Sistema PréCrime reduziu o número de crimes violentos em 99,8\% (DICK, 2012, p. 131), enfatizando o lado positivo da sujeição a tal sistema, muito semelhante ao que acontece com o discurso adotado nas políticas de privacidade ao afirmarem que a coleta de dados funciona para melhorar e personalizar a experiência de cada usuário. 
GUIRAU, Marcelo Cizaurre; FERREIRA, Ana Elisa S. C. da S. Minority Report e o governo da distopia algorítmica.PragMATIZES - Revista Latino-Americana de Estudos em Cultura, Niterói/RJ, Ano 10, n. 19, p. 232-248, set. 2020.

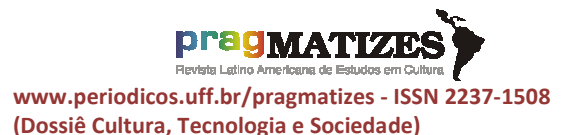

(Dossiê Cultura, Tecnologia e Sociedade)
Mas, assim como no conto, o preço a se pagar pela segurança é elevado. A personalização dos serviços tornou-se pouco a pouco uma manobra de modulação de comportamentos, estratégia amplamente utilizada no capitalismo de vigilância que tem desdobramentos profundos no Estado de direito.

\section{Referências bibliográficas:}

ADORNO, T. W. As estrelas descem à terra: a coluna de astrologia do Los Angeles Times: um estudo sobre superstição secundária. São Paulo: Editora UNESP, 2008.

BOTELLO, N. A América Latina e o apocalipse: ícones visuais em Blade Runner e Elysium. In: BRUNO, F. et al. Tecnopolíticas da Vigilância: perspectivas da margem. São Paulo: Boitempo, 2018.

DEBRAY, R. Civilization: How We All Became American. New York: Verso, 2019.

DEBRAY, R. Transmitir: o segredo e a força das idéias. Petrópolis, RJ: Vozes, 2000.

DICK, P. K. Realidades adaptadas: os contos de Philip K. Dick que inspiraram grandes sucessos do cinema. São Paulo: Aleph, 2012.

DONEDO, D.; ALMEIDA, V. O que é governança de algoritmos In: BRUNO, F. et al. Tecnopolíticas da Vigilância: perspectivas da margem. São Paulo: Boitempo, 2018.

DRESSEL, J.; FARID, $\mathrm{H}$. The accuracy, fairness, and limits of predicting recidivism. Disponível em: https://advances.sciencemag.org/conte nt/4/1/eaao5580

FINN, E. What Algorithms Want: Imagination in the Age of Computing. Cambridge: MIT Press, 2017.

HARARI, Y. Homo Deus: Uma breve história do amanhã. São Paulo. Companhia das Letras, 2015.

IERARDO, E. Mundo Virtual: Black Mirror, posapocalipsis y ciberadicción. Buenos Aires: Continente, 2018.

JAMESON, F. Pós-modernismo: a lógica cultural do capitalismo tardio. São Paulo: Ática, 2000.

LARREGUE J., WANNYN W.; DARTIGUES L. Vérité romanesque et fictions scientifiques: Philip K. Dick chez les criminologues. Socio [En ligne], 13 | 2019, mis en ligne le 08 janvier 2020. Disponível em: http://journals.openedition.org/socio/78 19. Acesso: 12 mar. 2020.

LÉVY, P. As tecnologias da inteligência: o futuro do pensamento na era da informática. São Paulo: Editora 34, 2016.

LÉVY, P. Cibercultura. São Paulo: Editora 34, 2014.

O'NEIL, C. Weapons of Math Destruction: How Big Data Increases Inequality and Threatens Democracy. New York: Broadway Books, 2016.

ROUVROY A.; BERNS T. Governamentalidade algorítmica e perspectivas de emancipação: o díspar como condição de individuação pela relação? In: BRUNO, F. et al. Tecnopolíticas da Vigilância: perspectivas da margem. São Paulo: Boitempo, 2013.

SIBILIA, P. Você é o que o Google diz que você é: a vida editável, entre o 
controle e o espetáculo. In: BRUNO, F. et al. Tecnopolíticas da Vigilância: perspectivas da margem. São Paulo: Boitempo, 2018.

SILVEIRA, S. A. D. Tudo sobre tod@s: redes digitais, privacidade e venda de dados pessoais. São Paulo: SESC São Paulo, 2017.

ZUBOFF, S. Big other: Capitalismo de vigilância e perspectivas para uma civilização de informação. In: BRUNO, F. et al. Tecnopolíticas da Vigilância: perspectivas da margem. São Paulo: Boitempo, 2018.

ZUBOFF, S. The Age of Surveillance Capitalism. v. 1. New York: Public Affairs, 2019. 